\title{
LA CONTRIBUCIÓN DIRECTA Y LA CAPITACIÓN EN CHIAPAS Y GUATEMALA EN LAS DÉCADAS REPUBLICANAS
}

\author{
DIRECT CONTRIBUTIONS AND CAPITATIONS IN CHIAPAS \\ AND GUATEMALA DURING THE REPUBLICAN DECADES
}

Aaron Pollack

Recibido: 07/11/2018 - Aceptado: 14/03/2019

\begin{abstract}
Resumen
No obstante su historia común como partes de la misma audiencia española, Chiapas y Guatemala elaboraron sistemas fiscales diferentes al separarse políticamente. Este artículo discute las diferencias en estos sistemas en relación a la capitación y las contribuciones directas, y analiza cómo fueron implementados en ambos territorios, las discusiones en torno a su legislación, las formas de su aplicación y el entorno social del cual formaban parte. Las contribuciones directas proporcionales en Guatemala nunca pudieron aplicarse en Chiapas. Estos impuestos se traslapaban con otras formas recaudatorias, especialmente durante las guerras. A veces se aplicaban con violencia y a menudo provocaron resistencia popular, lo que influiría en su eliminación en Guatemala con la llegada al poder de Rafael Carrera.
\end{abstract}

Palabras clave: Guatemala, Chiapas, capitación, contribución directa, periodo republicano.

\begin{abstract}
Notwithstanding their common history as parts of the same Spanish audiencia, Chiapas and Guatemala developed different fiscal systems when they separated politically. This article discusses the differences in these systems in relation to capitations and direct contributions, and analyzes their implementation in both territories, the discussions surrounding their legislation, the ways in which they were applied and the social realities of which they formed part. The proportional direct contributions in Guatemala could never be applied in Chiapas. These taxes overlapped with other forms of appropriation, particularly during the wars. At times they were applied violently and they often provoked popular resistance, which would have an impact on their elimination in Guatemala when Rafael Carrera came into power.
\end{abstract}

Keywords: Guatemala, Chiapas, capitation, direct contribution, Republican Period. 


\section{Introducción}

Los caminos políticos de Chiapas y Guatemala se habían bifurcado al finalizar el primer cuarto del siglo XIX y durante los siguientes años cada uno formaba un estado $^{1}$ en sus respectivas federaciones. Este artículo trata de la manera en que estos senderos se diferenciaban en el campo de la fiscalidad, específicamente en las capitaciones y contribuciones directas, la legislación en su entorno y las realidades sociales de las que formaban parte. ${ }^{2}$

En el primer apartado del artículo se discute la capitación y los esfuerzos por aplicar una contribución directa en Chiapas. Entre 1827 y 1833, los diferentes gobernadores chiapanecos mostraron mucha inquietud por convertir la capitación implementada en 1824 en una contribución directa proporcional, pero sería la llegada de los gobiernos centralistas mexicanos, en las décadas posteriores, que permitiría legislar algunas contribuciones directas. En la práctica, sin embargo, las nuevas leyes centralistas tuvieron poco impacto en Chiapas e incluso, al parecer, los montos recaudados por las diferentes contribuciones directas en el departamento nunca se enviaron a la Ciudad de México, sino que fueron utilizados para solventar los gastos locales. Como ocurrió en el resto de Hispanoamérica, el poder de los intereses establecidos, a todos niveles de la sociedad, frenó la posibilidad de que las reformas fiscales pudieran tener impactos profundos (Pollack, 2016).

En Chiapas y Guatemala, las guerras de la tercera y cuarta década del siglo XIX significaron mayores necesidades fiscales y mayores dificultades por enfrentarlas. Esta situación permite apreciar una continuidad entre el saqueo, una actividad propia de la guerra, formas de apropiación como los préstamos forzosos y voluntarios, los donativos, y los demás impuestos, entre ellos las contribuciones directas y las capitaciones. Lo anterior pone retos al historiador que intenta distinguir entre estas diferentes formas de recaudación y este artículo se limita a comparar las capitaciones y contribuciones directas implementadas en Chiapas y Guatemala durante estos años política y socialmente convulsos. El segundo apartado del artículo retoma estas problemáticas, además de discutir la resistencia que los pueblos e individuos desarrollaron ante los intentos por realizar los cobros de las diferentes contribuciones.

El tercero y último apartado del artículo se enfoca en las modificaciones en el cobro de las contribuciones directas, entre ellas la capitación, en Guatemala después de la Primera Guerra Federal centroamericana (1826-1829) y en cómo estas modificaciones se relacionaron con la rebelión de La Montaña, la caída del Estado de Los Altos y la toma la llegada del poder de Rafael Carrera en 1838. De particular interés son las formas en que las contribuciones directas se cobraron a nivel local, la discusión que precedió la aprobación de una contribución única en 1837 y los intentos iniciales por elaborar los censos que habrían permitido su aplicación. 


\section{Inquietudes sobre la proporcionalidad en Chiapas y acciones sobre la misma en México}

En Chiapas (Figura 1), como excepción al ímpetu inicial hacia la aplicación del principio de la proporcionalidad en las contribuciones directas en Hispanoamérica (Pollack, 2016), el 1 de marzo de 1824, unos veinte días antes de convocar a los partidos a una reunión para decidir la posible adhesión del territorio a México o Centroamérica, la Junta Provisional decretó una capitación universal de un real por mes, aplicable a todos los hombres adultos y las mujeres con capacidad económica. Para subrayar la importancia que tenía la cuestión fiscal en ese momento, en la convocatoria para el voto mencionado, se indica "nadie mejor que ellos, sobre quienes ha de gravitar el día de mañana el peso de las contribuciones directas o indirectas, podrá acertar en la elección a la nación a que se federen". ${ }^{3}$

El decreto de la contribución personal chiapaneca del 1 de marzo de 1824 indicó que debía comenzar a aplicarse de inmediato. A pesar de que el gobernador del estado en 1826 indicó que los cobros habían comenzado en 1825, existen varias referencias que demuestran sus inicios en 1824, de manera que empezó casi contemporáneamente con la contribución directa de la Federación Centroamericana, aproximadamente dos años después de la eliminación del tributo. ${ }^{4}$

Figura 1

CHIAPAS, 1825

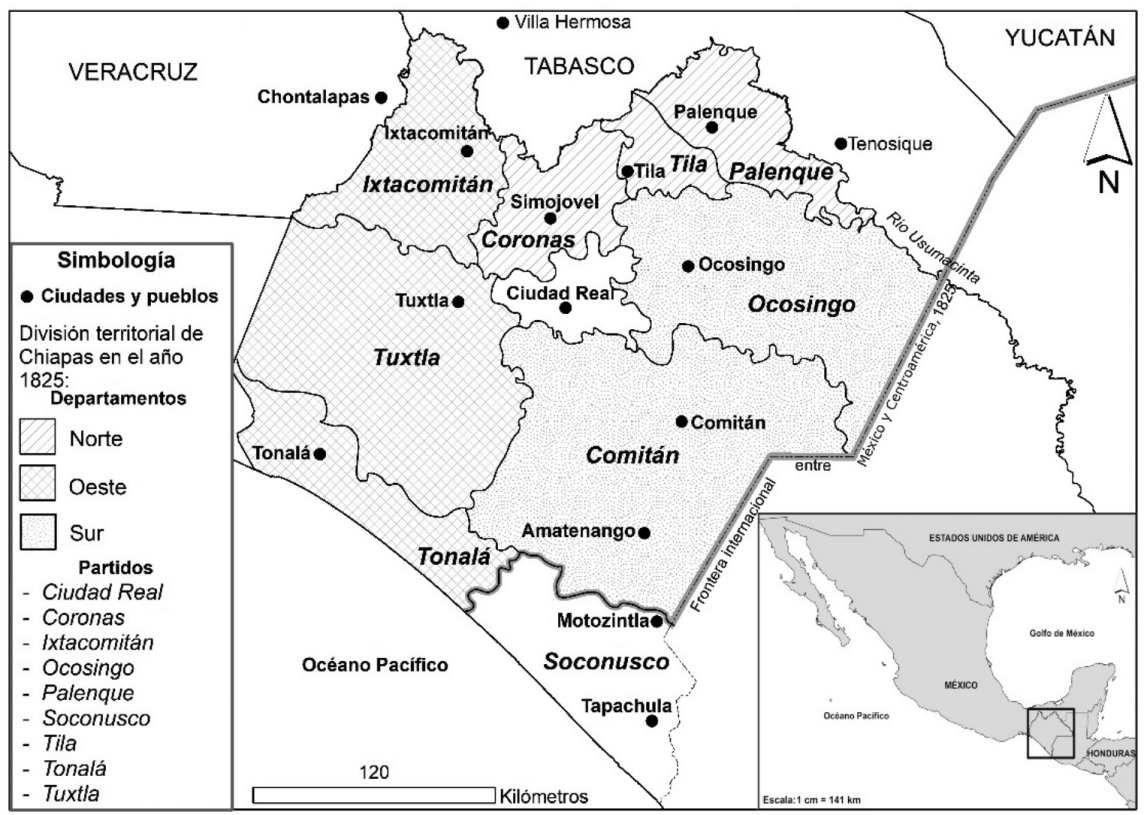

Fuente: Elaborado por Ulises Ramírez Casas a partir de Torres Freyermuth; Andriveau-Goujon; Vandermaelen et al.; García Cubas 22. 
"Siendo el ramo contribución casi el único con que cuenta el Estado para sus necesarias y preferentes atenciones", ${ }^{5}$ las dificultades en el cobro que aparecían a todas luces en el estado de Chiapas durante los siguientes años causaron preocupación y provocaron la elaboración de decretos y oficios, como demuestran las Memorias de los gobernadores citadas (Nota N. ${ }^{\circ}$ ) y varias referencias sueltas a las repetidas exigencias del gobierno estatal. ${ }^{6}$ Las autoridades chiapanecas compartían la impresión que los ingresos provenientes de la capitación sufrían por una ineficiencia en el cobro, lo que se demuestra también en los decretos que pedían la elaboración y entrega de los padrones de contribuyentes y el nombramiento de colectores (Sánchez Rafael). Un oficio elaborado por el Tesorero general del Estado de 1827 demuestra la desesperación de las autoridades:

Son repetidos los reclamos que por esta Tesorería se han remitido o dirigido a los Ayuntamientos y colectores responsables a [la contribución] para que solventen los adeudos correspondientes al año próximo pasado y hasta esta fecha no ha surtido el efecto que era de esperarse.

Efectivamente, unos meses después de producirse el oficio anterior, el gobierno del estado amenazó a los pueblos de un partido (no identificado) con el envío de las fuerzas de orden si no satisfacían la contribución y, además, publicó la amonestación en la prensa. ${ }^{8}$

Los gobernadores de Chiapas Diego de Lara (1826-1830) y el Col. José Ignacio Gutiérrez (1830-1832), este también comandante de la guarnición federal en la capital del estado de Chiapas, resaltaron la inequidad de la capitación personal. Desde principios de 1827, Lara indicó la importancia de "exigir [este impuesto] con igualdad, lo que puede conseguirse por el medio generalmente adoptado de la división de clases" y consideró que la contribución era "capaz por sí solo de subvenir a las erogaciones públicas, dándole nueva forma semejante a la que se ha dado en otros estados de la federación". ${ }^{9}$

El siguiente año apuntó que "esta renta tiene todos los caracteres de injusta por su falta ed [sic] equidad" recalcando que "además de la falta de propocion [sic] con que se halla impuesta esta contribución, hay vicios tan crasos en el método de recaudarla que la hacen más sensible" y que "la misma naturaleza de esa contribución está manifestando que arreglada a los principios de equidad y orden como es de esperarse será capaz de cubrir la mayor parte de las cargas públicas". En 1829 Lara resaltó que en cuanto a la Hacienda del estado, "[s]us ramos y su administración son las mismas del año anterior, y convienen las mismas providencias que se propusieron", antes de especificar más en 1830:

Si a los censos se añade el de la riqueza, propiedad e industria de los ciudadanos, está formada la estadística, y por ella se saben los frutos y rendimientos de un año, y sabiéndose estos se podrá saber hasta dónde se pueden extender las contribuciones. ${ }^{10}$ 
Si al nivel estatal, estos comentarios en torno a la implementación de alguna forma de contribución directa proporcional no dieron resultados ni en términos de leyes y decretos, el debate sobre este tema seguía vigente en la ciudad de México e incluso el decreto de una contribución directa nacional que proponía cobrar a cada individuo una cantidad correspondiente a lo ganado en tres días de trabajo, decretada el 27 de junio de 1823 unos meses después de la caída de Iturbide, siguió vigente -aunque no aplicado- hasta abril de $1831 .^{11}$ En 1829, mientras el gobernador de Chiapas proponía una contribución más ecuánime, el gobierno del presidente Vicente Guerrero, con Lorenzo de Zavala como Ministro de Hacienda, hizo iniciativas para cobrar una contribución directa progresiva sobre la renta, pagos de derecho de patente sobre el capital en giro y sobre fincas rústicas y urbanas con un valor mayor de 500 pesos. La contribución directa sobre la renta contemplaba que sobre las rentas de entre 1000 y 10000 pesos se pagara el 5 por ciento y que sobre rentas mayores a los 10000 pesos se pagara el 10 por ciento, excepto en el Distrito Federal, donde se pagaba el equivalente de 1 por ciento sobre el capital en giro (Hernández Jaimes, 2013). El día antes de que estas iniciativas se aprobaran en el congreso federal, se republicó en el Para-Rayo de la Capital de Chiapas, un artículo del Correo favorable a estas reformas. Después de descartar propuestas de préstamos forzosos y contribuciones indirectas, el artículo refirió a las ventajas que tenía la ley propuesta por Zavala:

Tiene cierta igualdad, pues se cobra en proporción a las rentas o productos líquidos de los propietarios y empleados; que no presiona a los pobres pues solo exige a los que tienen sueldo, rentas o ganancias de más de un mil pesos: en una palabra, que hace contribuir a muchas clases que hasta hoy no han hecho sacrificio por la libertad e independencia. ${ }^{12}$

En números posteriores, el periódico le dio seguimiento a las discusiones sobre la ley, en términos generalmente favorables, y publicó una copia completa de ella, además de unas críticas sobre su posible tendencia centralista. ${ }^{13}$

Finalmente, el Para-Rayo publicó también su propia conclusión que la ley no se pondría en práctica, lo que efectivamente ocurrió, como señaló Hernández Jaimes (2013), por la resistencia de las legislaturas estatales, de la prensa y de los sectores afectados. ${ }^{14}$ Sería solo a partir de 1835 que los gobiernos centralistas mexicanos tendrían la fuerza suficiente para implementar contribuciones directas cuyos impactos se sentirían, aun si con poco impacto, en Chiapas.

En tanto, en 1831 el gobernador y comandante José Ignacio Gutiérrez remarcó en su Memoria sobre la administración pública en Chiapas, a tono con lo planteado por su predecesor Lara y también con la ley propuesta por Guerrero en su momento, que "la cuota de la contribución capital, sin hacer novedad en los indígenas, se suba progresivamente en las otras clases, con proporción a sus mayores goces, y buscando siempre el nivel relativo a las fortunas" ("Memoria", 1830, 22). ${ }^{15}$ 
Como se ha constatado, Chiapas estuvo entre los pocos territorios hispanoamericanos en que no se propuso aplicar una contribución directa graduada, de algún tipo u otro, al implementar su primer sistema tributario independiente (Pollack, 2016). Sin embargo, hay que subrayar que en las Memorias que presentaron los gobernadores correspondientes a los años entre 1826 y 1830, se mostraba una preocupación por la poca equidad en el sistema fiscal, particularmente en su rubro más importante, la contribución, además de llamadas para su reforma. En lo que puede considerarse como un paso más en este esfuerzo (que nunca se concretizó), el controvertido gobernador Joaquín Miguel Gutiérrez decretó un reglamento sumamente extenso para la elaboración de padrones que indicaba a los prefectos recabar informaciones bastante generales sobre los diferentes pueblos. El reglamento solicitaba una clasificación de diferentes clases de "capitalistas", de haciendas de ganado mayor y ganado menor, de labranzas y también información sobre diferentes valores de las casas y otros edificios.

En general el reglamento debe entenderse como una herramienta que habría permitido la aplicación de una contribución directa de alguna manera graduada, desde mi perspectiva como la implementación de ideas circuladas por los gobernadores anteriores y la ley aprobada por Zavala y Guerrero unos años antes. El preámbulo del mismo decreto indicó que los censos debían producir tantas ventajas al Estado, "siendo la más principal el aumento y arreglo de la hacienda pública sin necesidad de aumentar las contribuciones". Se planteaba que los datos del censo podrían "servir de norte al legislador para hacer la felicidad pública". ${ }^{16}$

En un primer momento entre 1835 y 1838, el nuevo sistema fiscal nacional propuesto por los centralistas incluía impuestos sobre las fincas urbanas y rústicas y el pago de derechos de patentes (Sánchez Rodríguez), todo lo cual, por lo visto, en Chiapas reditó muy poco para las arcas nacionales en este primer periodo. Según el Tesorero de Chiapas, hacia finales de 1836, el 7 por ciento de lo recaudado que se concedía a los recaudadores ni cubría el costo de la tinta. ${ }^{17}$ Un año después, el recientemente llegado Administrador Principal de Rentas Nacionales de la capital de Chiapas dio una descripción reveladora sobre el funcionamiento de la fiscalidad mexicana en este departamento y puso en discusión la posibilidad que la falta de ingresos mencionada por el Tesorero se debía, por lo menos en parte, a una falta de empeño:

El archivo de esta oficina se compone de papeles sueltos y libros mal ordenados cuyas cuentas en globo no ofrecen luces para poderse dirigir; no tiene la oficina un solo utensilio, todo manifiesta el total abandono con que ha sido tratado, pues se hallaba la oficina en una tiendecita reducida de la plaza pública, en donde despachaba el Receptor a los que le buscaban (y esto les costaba algunos viajes.) El comercio nunca había conocido Aduana si no es para sacar los pases de los cargamentos que extraen, de modo que hoy que me hallo con la ley en la mano ordenando todo, y saliendo en persona a las entradas para hacer reconocer al comercio la Aduana les ha pesado 
tanto que se han tornado enemigos míos; pero Señor si en esta vez no procuro cortar el abuso del comercio estorbando las introducciones clandestinas de centro América jamás tendrá el erario nada por alcabalas. ${ }^{18}$

Como ocurrió en otros departamentos, hubo resistencia en Chiapas al pago de los dos y tres por millar sobre fincas rústicas y urbanas, como lo mencionó Trens en su momento. El Tesorero de Chiapas escribió al Administrador General de las Contribuciones Directas en 1836 que los propietarios no habían hecho los pagos correspondientes por sus diferentes actividades y por "otras circunstancias que dejo a la penetración de V.S. y por lo mismo siendo también que muchos no se presentarán e incurrirán en el aumento progresivo hasta procederá a la ejecución" (Trens 352). El Tesorero Correa consideraba que las multas aplicadas a los contribuyentes ocasionarían "disgusto" y que podrían "acaso producir alguna alarma”, por lo que solicitó -sin éxito- que no se aplicaran. ${ }^{19}$ A finales de 1837, se abandonó el cobro de estas contribuciones a nivel nacional (Piquero). ${ }^{20}$

En marzo de 1841, en un intento claro por aplicar un impuesto graduado, el congreso mexicano legisló una contribución personal que establecía cinco clases de contribuyentes que debían pagar entre 1 real y dos pesos al mes (Piquero; Torres Medina). Como explica el gobernador del departamento en un oficio de finales de marzo de 1842, el impuesto nunca se impuso en Chiapas porque antes de comenzar su aplicación, se había decretado que en los departamentos donde ya existían contribuciones personales, podían mantenerse los métodos de recaudación y las cuotas existentes. ${ }^{21}$ En vez de aplicar una contribución graduada por clases como la que se había aprobado a nivel nacional, similar a lo que de alguna manera habían propuesto Diego Lara y Joaquín Miguel Gutiérrez, en Chiapas se optó por mantener la capitación universal de 12 reales anuales.

No obstante el envío del oficio mencionado, unas días después el gobierno de Santa Anna decretó el establecimiento de una capitación mencionando específicamente que los gobiernos de los departamentos de Oaxaca y Yucatán podían optar por continuar con el cobro de la contribución personal existente, sin mencionar el caso, bastante similar, de Chiapas. ${ }^{22}$ Ante esta situación, el gobernador de Chiapas envió un oficio al Director de Rentas Generales reiterando que en Chiapas nunca se había aplicado la capitación de 1841 por lo que no se enviaban las informaciones correspondientes sobre su cobro. ${ }^{23} \mathrm{~A}$ pesar de haberse trasladado este expediente al Ministro de Hacienda, no se encuentra respuesta en la documentación. En los informes mensuales enviados de Chiapas al Ministro de Hacienda correspondientes a 1843, sin embargo, se incluía la información sobre el cobro de la capitación, aunque, al parecer, los ingresos chiapanecos no se enviaron a la ciudad de México, sino que fueron ejecutados en el departamento. ${ }^{24}$ 
La ley mexicana de marzo de 1841, mencionada en el penúltimo párrafo, fue reformada en septiembre del mismo año eliminando el cobro a los jornaleros, artesanos y demás personas con ingresos menores a quinientos pesos anuales (Piquero). En enero de 1842 se abolió esta contribución para remplazarla con otras. La capitación de 1842, de un real al mes, como la que ya existía en Chiapas, formaba parte de un conjunto de contribuciones directas que contemplaba cobros a diferentes clases de la sociedad a través de impuestos sobre la propiedad (fincas urbanas y rústicas), sobre las profesiones y ejercicios lucrativos, sobres sueldos y salarios, sobre objetos de lucro y sobre la industria (Piquero; Serrano Ortega). Es decir que, a diferencia de la contribución de 1841 que contemplaba el impuesto sobre la propiedad y luego un cobro graduado basado en los ingresos, la de 1842 cobraba las diferentes acciones que creaba ingreso, más una capitación general y el impuesto sobre la propiedad. Cabe notar que, por lo menos en 1843, se informaba sobre el cobro de los diferentes rubros en Chiapas, aun cuando en los documentos presentados los rubros de sueldos y salarios y de profesiones y ejercicios lucrativos resultan no haber causado ingresos al erario. ${ }^{25}$ Así mismo, en lo informado sobre lo recaudado en Chiapas en 1843, reitero, se indicó con claridad que todo ello se habría utilizado para los gastos departamentales y en apoyo a la guarnición militar. ${ }^{26}$

\section{Violencia, guerra, préstamos forzosos y resistencia}

En el estado de Guatemala (Figura 2), el cobro de la capitación fue una de las preocupaciones que motivó la participación de indígenas y ladinos en la Rebelión de La Montaña en 1837, la que hizo caer el gobierno de Mariano Gálvez y colocó a Rafael Carrera en el poder (Woodward). De manera similar, la resistencia a la contribución directa que se intentó aplicar en Salvador en 1832 provenía tanto de sectores indígenas como de ladinos (Lauria). En Chiapas, como se ha mencionado, las Memorias de gobierno de finales de la década de los veinte muestran reiteradas propuestas para una contribución con cierta proporcionalidad y puede imaginarse que había una renuencia por parte de los sectores con mayores ingresos a su implementación. Además, durante los años del centralismo, los ingresos provenientes de las diferentes contribuciones directas que habrían correspondido a los sectores medios y altos (es decir, todas menos la capitación), fueron realmente pocos, un reflejo de la resistencia al pago que se había notado desde 1836 (Serrano Ortega). ${ }^{27}$ Sería solamente casi a finales del siglo XIX que los impuestos sobre la propiedad, en particular sobre las fincas rústicas, tomarían más importancia para el erario chiapaneco y desplazarían la capitación como el rubro principal de ingresos (Sánchez Rafael). 


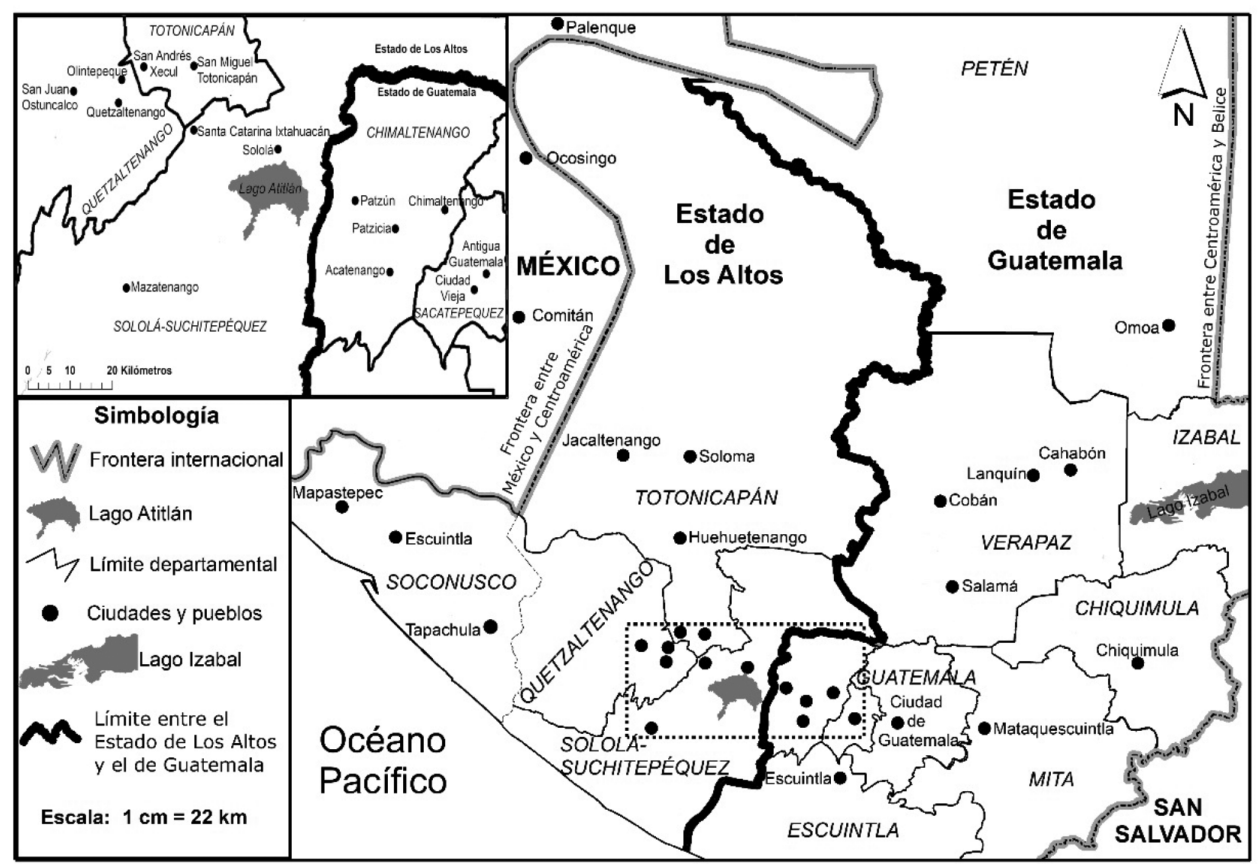

Fuente: Elaborado por Ulises Ramírez Casas a partir de Taracena Arriola et al.; Berghaus; Colton y Swainson.

Las poblaciones indígenas de los estados de Salvador y Guatemala participaron, a menudo como protagonistas, en las protestas y rebeliones que enfrentaron los gobiernos estatales en los años treinta del siglo XIX. En el caso guatemalteco, estas acciones contribuyeron a las caídas de los gobiernos del estado de Guatemala (1837-1838) y el de Los Altos (1840) (Taracena Arriola; Woodward; Pollack, 2013). Asimismo, como se ha mencionado, ante la implementación de una capitación nacional a partir de 1840, indígenas en muchos departamentos del centro de México opusieron resistencia y, en el departamento de México donde la rebelión (aquí asociada con otros motivos) tuvo más arraigo, lograron, si bien provisionalmente, la aplicación de una exención para los jornaleros y sirvientes que ganaban menos de 300 pesos anualmente (Guardino; Hernández Jaimes, 2003; Serrano Ortega).

La resistencia al cobro de las diferentes capitaciones en el estado de Guatemala puede entenderse como una continuación de una resistencia al cobro del tributo que parecer haberse empezado a tomar importancia en la primera década del siglo XIX con 
el intento por implementar una uniformización en el cobro del tributo y a fortalecerse con la reimposición del tributo (llamado contribución oficialmente) en 1815 (Fernández Molina). Se trata de una cultura política subalterna que se estaba desarrollando y que incluía varias formas de resistencia, entre ellas la violencia.

Si la capacidad de cobrar impuestos o derechos puede ser un indicador del ejercicio del control sobre un territorio, la necesidad de usar la violencia para recaudar impuestos o derechos es una muestra de la debilidad de este control. En los casos de Chiapas y Guatemala, sabemos de algunos momentos en que se aplicó la violencia o la amenaza de la violencia para asegurar el cobro de la capitación. Puede resultar innecesario subrayar que en momentos de guerra las imposiciones fiscales se volvieron primitivas. Las partes bélicas exigían no solo el servicio militar y el pago de donativos, préstamos, contribuciones extraordinarias y demás, sino también los bienes encontrados en el campo que pudieran utilizarse para la guerra o la manutención de la tropa. Además, estas exigencias podían más fácilmente volverse agresivas en una situación de guerra donde la violencia era de por sí más generalizada. En algún sentido, el saqueo como mecanismo para alimentar y contentar a las tropas, e incluso para transportarles a ellas y los enseres de la guerra, es ejemplo de la fiscalidad en su forma más básica.

Es obvio que las imposiciones en términos de requisiciones de alimentos, animales de carga y de montar, como otras, afectaron mayormente a las regiones en que las guerras se desarrollaban de manera más crujiente, como el oriente guatemalteco y el occidente salvadoreño en la Guerra Federal centroamericana (1826-1829) (Sarazúa Pérez, 2007; Taracena Arriola). ${ }^{28}$ Sin embargo, aun las regiones lejanas de los conflictos podían encontrarse en condiciones similares, como ocurrió en Los Altos de Guatemala durante estos mismos años donde en 1826 un comandante de las fuerzas del estado de Guatemala exigió, de manera violenta, caballos de la población de Quetzaltenango (Taracena Arriola). ${ }^{29}$ En estos mismos días, en su afán por encontrar recursos de manera urgente, el gobierno del estado de Guatemala buscaba asegurar un préstamo de la Iglesia quetzalteca, con la idea de usar los títulos de la tierra municipal de la misma localidad, para entonces en manos de las autoridades indígenas de la ciudad, como garantía. Fue esta una razón más que provocara la ira de la muchedumbre que dio muerte al Vice-Jefe del gobierno del estado, Cirilo Flores, en ese entonces actuando como Jefe de gobierno, ante el arresto de Juan Barrundia. ${ }^{30}$ De igual manera, se puede referir la aceptación de leña como pago de la alcabala del pueblo de Olintepeque, ubicado en las cercanías de la misma ciudad, en febrero de 1829, o la quema del pueblo de San Andrés Xecul, vecino de este, en estas mismas fechas, por no proporcionar soldados o recursos a los militares guatemaltecos que se esforzaban por mantenerse en pie ante la inminente victoria de Morazán (Mackenzie; Pollack, 2008; Sarazúa Pérez, 2013).

Desde finales del siglo XVIII, las contribuciones extraordinarias españolas, aplicadas en general para financiar las guerras inter imperiales, se habían vuelto ocurrencias comunes y tuvieron sus recaídas en el reino de Guatemala en las elites y los 
pueblos de indios. Así que los préstamos forzosos y voluntarios, los empréstitos y donativos que aplicaron los gobiernos independientes fueron una continuación clara de esta política. ${ }^{31}$ En Chiapas, los préstamos otorgados, principalmente por la Iglesia católica y algunas personas pudientes, tuvieron una importancia particular al ser la fuente principal para el mantenimiento de la guarnición del ejército federal que se ubicaba en la capital del estado. Existen referencias a préstamos voluntarios, préstamos forzosos y empréstitos en Chiapas durante varios momentos entre 1823 y 1850 y los del periodo federalista han sido objeto de estudio por Rafael Sánchez. Los préstamos voluntarios se aplicaron en 1828, 1832, $1833^{32}$ y los forzosos en 1823-1824 (Torres Freyermuth), 1835, 1836, 1843 (Trens), 1850. ${ }^{33}$ Desafortunadamente, no existe mayor información sobre quiénes exactamente pagaron estos préstamos y los impactos sociales que hubieran tenido.

En 1824 se aplicó una contribución patriótica en Guatemala, por lo menos en Patzicía, a todos los hombres, quienes pagaban cantidades de entre medio real y dos pesos. El listado de los contribuyentes a esta subscripción se divide entre los "ladinos", que aportaban entre un real y dos pesos y los "naturales" cuya contribución era siempre de medio real. Estimo que entre dos terceras y tres cuartas partes de los ladinos listados en el documento pagaron y aproximadamente un $80 \%$ de los naturales. ${ }^{34}$ En abril de 1827, durante la guerra federal (1826-1829), se decretó un préstamo forzoso a aplicarse entre las personas económicamente pudientes, pero al ver su poco éxito, se extendió el alcance del decreto a toda la población el siguiente mes, de manera que esta contribución extraordinaria patriótica asemejara mucho a la contribución directa aprobada en 1825, con la diferencia que tasaba el uno por ciento sobre los productos o ganancias anuales, siempre con un cobro para las diferentes ocupaciones de entre 4 reales y 20 pesos, que es lo que el decreto guatemalteco de 1825 y el centroamericano de 1823 habían establecido (Sarazúa Pérez, 2013; Taracena Arriola). ${ }^{35}$

El siguiente año de 1828, se reformó y se aumentó la contribución de 1827 y, ante las siempre mayores dificultades, se duplicó el cobro en agosto, para luego en noviembre convertirla en una subvención temporal de guerra. Puede observarse los intentos repetidos por parte de las autoridades del estado de Guatemala por encontrar diferentes maneras de asegurar los recursos fiscales que financiarían la guerra, las que a veces se asemejaban más a una contribución directa proporcional, a veces a préstamos forzosos cobrados a los grupos pudientes de la sociedad. Asimismo, es fácil imaginar que muchas personas habrán vivido esta política fiscal, si así se le puede llamar, como una constante presión por parte de las autoridades.

\section{Los últimos años de la capitación en Guatemala, 1829-1839}

Con el fin de la guerra en 1829, el estado guatemalteco volvió a buscar una estabilidad fiscal y en particular la forma de aplicar una contribución directa que de alguna manera continuara con lo decretado en 1825. Un decreto de finales de 1829 
establecía una contribución directa con cuotas correspondientes a cada departamento del estado, lo que en abril de 1830 se convirtió en una contribución con carácter permanente. La contribución incluía un censo de 5 pesos anuales que pagaban hombres y mujeres con propiedades con un valor mayor de mil pesos, algunos profesionales y curas, dueños de varios negocios y arrendadores de fincas cuyo alquiler fuera mayor de 100 pesos al año. La ley de 1830 contemplaba el descuento del 2 por ciento de los sueldos de los militares y empleados civiles y finalmente una capitación de 12 reales al año que se aplicaba a todos los hombres entre 15 y 55 años, con excepción de los religiosos del convento de Belén y las personas que formaban el ejército federal o participaban en la milicia activa (Sarazúa Pérez, 2012).

Ante situaciones de penuria, la escasez de granos, un brote de viruela y, al parecer, una preocupación que el cobro de este impuesto podría ser aprovechado por los grupos opositores para promover el descontento entre la población, se suspendió el cobro de la capitación entre julio de 1831 y julio de 1832 (Sarazúa Pérez, 2012). Con el intento de invasión desde Soconusco en 1832 y la toma de Omoa en el mismo momento, se tuvo que exentar de la capitación a toda la población de Chiquimula en agosto de 1832, como reconocimiento de su actuar en la guerra (Sarazúa Pérez, 2015).

La contribución de 1830 se siguió cobrando sin modificaciones hasta 1834 cuando se bajó la cantidad de la capitación a 8 reales. Para estos años ya se había abierto una discusión sobre cómo enfrentar las debilidades en el sistema fiscal existente ante la resistencia de los contribuyentes y la corrupción de los recaudadores, lo que desembocó en el planteamiento de una ley de contribución única, que se aprobó en agosto de 1836 (Sarazúa Pérez, 2013). La nueva ley planteaba el cobro de un medio por ciento de impuesto sobre todas las formas de capital, además de mantener los cobros sobre la chicha y el aguardiente: eliminaba la capitación, las alcabalas internas, la contribución territorial y el censo. Cualquier propiedad con un valor mayor de cincuenta pesos sería afecto al impuesto, como también cualquier ingreso mayor a cincuenta pesos anuales (Sarazúa Pérez, 2013). ${ }^{36}$ En la primera mitad de 1837, se comenzó la elaboración de los padrones que el nuevo decreto ordenaba realizar y en este mismo periodo aparecieron una serie de levantamientos locales, algunos de los cuales finalmente llevarían a la rebelión de La Montaña.

Resulta notable que esta ley contemplara la eliminación de la capitación, una de las seis principales demandas enarboladas por los rebeldes de La Montaña (Memorias, 1906; Miceli). ${ }^{37}$ Resulta así mismo interesante que las Memorias del General Carrera refieren a una capitación de dos pesos anuales por persona, una cantidad que se había cobrado, o intentado cobrar, entre 1802 y 1811, en algunas regiones y que se propuso cobrar en octubre de 1839, pero que el mismo Carrera, ya en el poder, rechazó, como se verá más adelante. La capitación que se cobraba en 1837, el momento a que se refiere en las Memorias, era de ocho reales por persona, lo que hace pensar que en este aspecto el escrito probablemente se equivoca en su reconstrucción de los eventos. ${ }^{38}$ 
No obstante lo anterior, es probable que la iniciativa para eliminar la capitación en la ley de Hacienda de 1836 no provenía únicamente del interés en respetar la proporcionalidad o la equidad en el cobro de los impuestos, como se había planteado en la constitución de 1825 y se retomó en el mismo decreto y en los periódicos oficiales de la época. ${ }^{39}$ La resistencia a la contribución, como se ha mencionado, impactaba a las discusiones sobre la fiscalidad desde años atrás, por lo que podría verse el intento por eliminar la capitación en 1836 como un esfuerzo por frenar problemas que las autoridades veían desarrollándose en los pueblos.

Aunque los datos sobre el nivel de resistencia al cobro de la contribución en el periodo entre 1823 y 1839 en Guatemala son relativamente escasos, se nota una cierta continuidad con la oposición al cobro del tributo español: la renuencia al pago, la huida para evitar el cobro y la tardanza en pagar. Sin embargo, en el periodo republicano, los documentos hacen referencia a acciones en el proceso de cobrar que no aparecen en los expedientes coloniales. En algunos casos, esta situación puede derivarse de cambios ocurridos a nivel de gobierno municipal que hayan facilitado acceso a información sobre formas de cobro ya existentes. Me explico: bajo la dominación española, afuera de unas pocas ciudades y villas en el reino de Guatemala, los gobernadores y alcaldes indios se encargaban del cobro del tributo, pero con la creación de los ayuntamientos constitucionales, los encargados del cobro de la capitación en los pueblos más grandes serían los ladinos que lograron tomar el control del gobierno municipal. Podría imaginarse que la presencia de alcaldes ladinos habría significado una mayor producción de documentos sobre sus acciones al interior del pueblo, así que la mención de la presencia de tropas y el embargo de bienes que se encuentra en expedientes del periodo republicano puede significar la aplicación de nuevos mecanismos de cobro, o simplemente la existencia de una documentación que permite apreciarlos mejor.

En la práctica, con el nuevo sistema, los gobiernos municipales tenían la facultad de encarcelar a los contribuyentes, lo que había ocurrido con el tributo español (Fry), pero también de embargar sus bienes, sobre el cual no tenemos referencia en el periodo colonial. Además, bajo el sistema español, los alcaldes mayores o corregidores encarcelaban a los alcaldes o los gobernadores de los pueblos, pero en el periodo republicano, no se ha encontrado referencia a tal práctica.

En el pueblo de Chimaltenango, algunos individuos y "los demás del calpul del Pueblo" se quejaron en 1831 que se les había encarcelado y embargado sus azadones y machetes, una dinámica que se refiere muy claramente en las Memorias del General Carrera (18) en el pueblo de Mataquescuintla, departamento de Chiquimula. ${ }^{40}$ Dos descripciones de 1835 refieren al proceso de la recaudación en el cercano pueblo de Patzicía y sus apreciaciones se reflejan en otros documentos de la época: 
Tan pronto como los indios advierten que se está cobrando la contribución, dejan sus miserables casas abandonadas y se huyen a los montes, no dejando cosa alguna que poder embargarlos. A los montes también hemos ido a perseguirlos y en ellos ha tenido el mismo resultado, como le consta de vista al sargento y a todo el piquete que vino de auxilio, como también... los pocos que llegan a caer en manos de los comisionados y que se reducen a las cárceles. ${ }^{41}$

[La corporación municipal] ha agotado todos los esfuerzos que han estado a su alcance, ha salido a los montes personalmente en solicitud de los dispersos, ha procurado sorprenderlos en sus propias casas de deshoras de la noche y ha practicado cuantos medios puede contarse en la eficacia más activa; pero no ha sido posible encontrarlos en sus casas ni menos cosa alguna para poderles embargar para subastarla. ${ }^{42}$

Los ediles patzicenses no solo encarcelaban y embargaban los bienes de los contribuyentes (o por lo menos los "indios"), sino que los buscaban en los montes, a veces con el apoyo de una fuerza armada. Efectivamente, existen varios documentos que refieren a peticiones realizadas por los gobiernos municipales para el apoyo de una fuerza armada para el cobro de la capitación o de alguna manera de la presencia de la fuerza armada durante la recaudación, lo que no resulta en la documentación colonial. El gobierno municipal de Patzún en 1830 indicó que no quería solicitar la fuerza armada, porque solo implicaba que las personas huirían..$^{43}$ En un parte oficial fechado en Totonicapán del 8 de diciembre de 1836, el Comandante de la Cuarta División, Agustín Guzmán, indicaba que se encontraba en Soloma, en el partido de Huehuetenango, por el "deseo de efectuar el establecimiento de escuelas Dominicales, la siembra de comunidad, y el cobro de contribución, también de comunidad, y los demás objetos de que habla el estatuto de instrucción primaria". ${ }^{4}$

Como se menciona en el mismo parte oficial y en el bando circulado por el Comandante General del Departamento de Chiapas que se reproduce en el mismo número del Semanario, se trata de los momentos en que el entonces exgobernador chiapaneco Joaquín Miguel Gutiérrez, mencionado arriba, preparó y realizó una incursión militar partiendo de Los Altos guatemaltecos para adentrarse en Chiapas. En octubre de 1839, ya con la capitación reducida a la mitad y a escasos dos meses antes de su eliminación, el Jefe Político de Chimaltenango amenazó al pueblo de Acatenango el envío de un piquete de soldados si no se entregaba la contribución debida dentro de quince días. ${ }^{45}$

La documentación referida al tributo español indica que los alcaldes o gobernadores de los pueblos viajaban para entregar el tributo en las cabeceras de las alcaldías mayores y corregimientos, de manera que el cobro de este derecho señorial no habría sido motivo para presentarse las fuerzas armadas en los pueblos. En los casos conocidos dónde la fuerza armada se involucraba con cuestiones del tributo español, su presencia tendía a vincularse no con el cobro como tal, sino con 
conflictos políticos locales o regionales que de alguna manera tenían el tributo como uno de sus factores propiciadores.

Considerando las complicaciones que la capitación implicaba, tal vez no sea de sorprenderse que el presidente de la Asamblea Legislativo del estado de Guatemala, al abogar por la contribución única que se había aprobado en agosto de 1836, indicara que su propuesta era "solo para hacer efectivo, sin vejaciones personales, ni violencia alguna, el artículo constitucional que quiere contribuyan todos los habitantes en proporción a sus facultades. Así cuida el proyecto de la igualdad constitucional, huyendo de la capitación" ${ }^{46}$ Claro está que las vejaciones que provocaba la contribución directa ocurrían no solo en el cobro de la capitación sino que también en la del censo, como se puede inferir de los comentarios vertidos por el periódico quetzalteco El ciudadano en 1836 que suplicaba a los miembros de la legislatura estatal que modificara las leyes "quitando las duras y pesadas cargas de contribución directa" a la vez que "decret[as]en lo que favorezca más la propiedad y la persona de los Ciudadanos" ${ }^{4}$

En julio de 1837, en dos pueblos del departamento de Sololá y en la villa de Huehuetenango, hubo cuestionamientos de la ley de Hacienda de agosto de 1836: en Sololá, como menciona Taracena Arriola, el magistrado ejecutor indicó que en "este distrito solo con las armas se hará cumplir la ley de hacienda. En ninguno de los pueblos que lo componen se han practicado las regulaciones" y más específicamente que los "indígenas del Quiché y Joyabas [SIC] se oponen a que se les valoren sus intereses y han solicitado seguir pagando la contribución establecida". Asimismo, en la villa de Huehuetenango, algunos ladinos e indios se manifestaron frente a la casa del gobernador estar a favor de pagar la capitación y otros impuestos, en vez de aceptar a la nueva ley (Ingersoll; González; Taracena Arriola). ${ }^{48}$

Unos meses antes de los eventos descritos arriba, aparecieron en el departamento de Chiquimula en el oriente de Guatemala los inicios de lo que para junio de 1837 comenzaba a tomar la forma del levantamiento de La Montaña. Ya en marzo de 1837, además de lo mencionado en Sololá, Huehuetenango y Verapaz (Nota N. 49 ) los indígenas de San Juan Ostuncalco, en Quetzaltenango habían iniciado esta ola de protesta y rebelión. ${ }^{49}$ Como suele ocurrir en este tipo de situación, había razones de mediano plazo y otras más puntuales que empujaron a las personas hacia la protesta y la rebelión.

Conflictos sobre la tierra, que venían desde muchos años atrás, se mezclaban con las nuevas políticas de tinte liberal, como la legalización del divorcio, la confiscación de los bienes del clero, una serie de leyes que promovían el registro y entonces la titulación de la tierra y la aplicación del código de Livingston. La ley de Hacienda de 1836 preveía la medición de las tierras de privados y también de los ejidos de los pueblos, lo que provocó cierta resistencia también, como se ha notado. Además, en 1837 el cólera morbus entró a Guatemala desde el oriente y las peregrinaciones a Esquipulas en enero de este año coadyuvaron su extensión, especialmente en el oriente del estado y en los vecinos El Salvador y Honduras (Hall y Pérez Brignoli). 
La región oriental de Guatemala vivía cada uno de estos fenómenos (y de manera muy pronunciado el cólera), además de haber sido escenario principal de la Primera Guerra Federal (1826-1829) que significó una pérdida importante de vidas y de bienes en la zona, una situación que en parte se repitió durante los conflictos de 1832 en la que muchos soldados del departamento de Chiquimula participaron. Además, el gobierno del estado de Guatemala había promovido varios proyectos de colonización y en el oriente estos habían comenzado a funcionar, lo que creó tensiones, en parte por el envío de criminales condenados a las nuevas colonias, a veces con sus familias, como forma de castigo (Jefferson, 2015). Existía un grupo de hacendados medianos locales que apoyaba a la rebelión con recursos económicos, muchos de ellos con alguna herencia africana, lo que habría limitado su influencia en las altas esferas de la política guatemalteca, pero que probablemente fortalecía su posibilidad de crear un sentido de unidad regional al movimiento. Finalmente, había también un grupo del clero bajo, desafecto por las políticas liberales y en especial por sus impactos en su gremio, que apoyaban a las iniciativas rebeldes. ${ }^{50}$

Sin menospreciar las otras causas de la rebelión, Ralph Lee Woodward subraya también la importancia del cobro de la capitación que otros investigadores no mencionan con tanto hincapié en sus interpretaciones. ${ }^{51}$ Es de notarse los antecedentes locales: en 1821, con la independencia, los indígenas de Mataquescuintla (uno de los pueblos más importantes en la rebelión) solicitaron ser exentados del tributo y el siguiente año no lo pagaron; en 1824 el mismo pueblo rechazó el pago de la contribución, no obstante el hecho que, según el corregidor, todos los demás pueblos de Chiquimula pagaron (Fry). En 1832, como se ha mencionado, todo el departamento de Chiquimula fue exentado de la contribución por sus aportaciones a los esfuerzos de la guerra. Para 1834, las autoridades del departamento de Chiquimula indicaron que se había paralizado el cobro de la contribución directa y que los pueblos ignoraban la recaudación de impuestos (Jefferson, 2000). Si lo anterior no fuera suficiente para considerar la capitación como un elemento importante que propiciaba la rebelión, puede agregarse que a partir de ella nunca se cobró otra vez una capitación en Guatemala, a diferencia de todas las demás regiones hispanoamericanas con una presencia indígena importante en las cuales la capitación duraría por lo menos hasta la década de 1850 y en algunos casos, como el de Chiapas, hasta el siglo XX.

Resulta interesante que entre mayo y julio de 1837 algunos pueblos del oriente exigían la eliminación de la capitación mientras en otros del occidente se solicitaba pagarla, en vez de cumplir con lo que implicaba la nueva contribución única.

A raíz de la rebelión de Carrera, el Jefe de Estado Gálvez tomó poderes excepcionales en junio de 1837; en agosto del mismo año había terminado con el experimento de la contribución única y aplicado una contribución directa extraordinaria que afectaba, al parecer, principalmente a los propietarios (Marure; Rodríguez; Ingersoll). 
Al quedarse sin efecto la ley de Hacienda de 1836, seguía vigente el cobro de la capitación, aunque probablemente con poco efecto.

En esta coyuntura, las tropas de Carrera ganaban territorio en el oriente, en el occidente los intereses autonomistas en formar lo que poco después sería el estado de Los Altos se fortalecían y en la capital y en la Antigua Guatemala, el apoyo para Gálvez de su ala más liberal se desvanecía ante la centralización del poder efectuada en junio. En diciembre de 1837, Gálvez formó un gobierno que incluía a personajes de la élite guatemalteca, mucho más moderados en sus planteamientos y recientemente regresados del exilio. Entre los acuerdos del grupo que se reunió para formar este gobierno se encontraba la supresión de las contribuciones que pesaban más sobre las clases más pobres (Rodríguez; Woodward). En tanto, las fuerzas de La Montaña se fortalecían y entraron a la ciudad de Guatemala a finales de enero de 1838; aunque las tropas rebeldes ocuparon la ciudad poco tiempo, su presencia se sintió con fuerza. Un mes y medio después, el 17 de marzo, apareció en el periódico del gobierno el comentario que el impuesto de capitación no se podía cobrar "por que pesa sobre las clases indijentes (sic) y estas resisten pagarla" (Woodward 86). ${ }^{52}$ Para aquel entonces, Los Altos ya se había separado de Guatemala por lo que el decreto del 26 de julio que redujo la capitación a cuatro reales (Marure) solo impactaría a los cuatro departamentos restantes: Chimaltenango y Sacatepéquez, Guatemala y Escuintla, Verapaz y Chiquimula.

En cierto sentido, el último acto de lo que puede considerarse una lucha contra la capitación que había empezado en Guatemala en los primeros años del siglo XIX fue también el momento que propició la caída del estado de Los Altos: el rechazo al cobro de la capitación en Santa Catarina Ixtahuacán que llevó a la masacre de 39 indígenas del pueblo el 1 de octubre de 1839, a manos de las tropas del estado de Los Altos. La renuencia al pago de la contribución ocurría no solamente en Santa Catarina, sino en varios pueblos del departamento de Sololá, incluyéndose varios ubicados alrededor del lago Atitlán (Taracena Arriola). ${ }^{53}$ La resistencia de los pueblos de la región resultaba en parte del deseo de algunos de ellos de mantenerse como parte del estado de Guatemala y en parte de los esfuerzos del gobierno altense por construir un camino de Quetzaltenango a la costa sur en Suchitepéquez, en las tierras y con el mano de obra de los pueblos indígenas de la región. La masacre sirvió como pretexto para que Carrera, desde hace un tiempo el hombre fuerte en Guatemala, invadiera Los Altos en enero de 1840 y terminara con el sexto estado de la Federación Centroamericana (Taracena Arriola).

El 8 de octubre de 1839, una semana después de la masacre en Santa Catarina Ixtahuacán, se presentó un nuevo plan de contribuciones ante la Asamblea Constituyente del estado de Guatemala y se incluyó una capitación de dos pesos para todos los varones de 18 y 50 años. Con alguna variación en cuanto a las edades, esta iniciativa reprodujo exactamente lo que la Ordenanza de Intendentes de la Nueva España había propuesto unos cuarenta años atrás. Podría argumentarse que la implementación de 
este artículo de la Ordenanza, aplicada únicamente en el reino de Guatemala -y ni en todo su territorio-, había provocado la ola de resistencia al tributo que finalmente terminaría con los eventos de Santa Catarina. ${ }^{54}$

Si bien es cierto que para esta fecha todavía existía la capitación en el estado de Guatemala y que también en octubre de 1839 un jefe político en Chimaltenango tuvo a bien amenazar con el envío de tropas para exigir su cobro en el pueblo de Acatenango, no muy lejano de la frontera con Los Altos, ni de algunos de los pueblos que habían rechazado el pago de la contribución altense, es también cierto que el 4 de diciembre de 1839 - un mes y medio antes de que Carrera iniciara su marcha hacia Los Altos-, se decretó la eliminación de la capitación en el estado de Guatemala (Marure; Woodward). ${ }^{55}$

\section{Reflexión final}

Los caminos de la fiscalidad en Guatemala y Chiapas se bifurcaron a partir de 1823, no obstante la historia que habían compartido como partes de la audiencia de Guatemala. El estado/departamento de Chiapas aplicó una capitación que se mantuvo desde 1824 hasta la revolución mexicana y durante las primeras décadas de este periodo fue el sustento principal de su erario. Los deseos por transformar la capitación en una contribución directa proporcional durante la tercera y cuarta década del siglo XIX nunca dieron resultados.

Los gobiernos del estado de Guatemala intentaron aplicar diferentes contribuciones directas proporcionales y a veces tuvieron cierto éxito en este esfuerzo aunque aquella parte dirigida a los más pobres, a veces llamada capitación, siempre enfrentaba cierta resistencia, la que formaba parte de una ola de rechazo a este tipo de cobro que, al parecer nació en oposición al tributo español como fue aplicado en las décadas antes de la independencia.

Existen indicaciones de resistencia al cobro de la capitación en Chiapas también, aunque las referencias (como las fuentes en general) aparecen en menor número. Las autoridades a los dos lados de la frontera usaron la violencia para la recaudación y esta violencia se volvía más perceptible durante los momentos de enfrentamiento militar cuando los mecanismos utilizados como parte de un sistema fiscal se deslizaban hacia los préstamos (a veces forzosos) y donativos, los que a menudo se practicaban mientras los ejércitos realizaban saqueos, lo que tal vez podría considerarse la fiscalidad en su forma más primitiva.

\section{Notas}

1 Entre 1836 y 1846 las divisiones territoriales de la República Mexicana que habían sido "estados", se llamaron "departamentos".

2 El término "contribución directa" puede entenderse como un impuesto cobrado a un individuo o una empresa y una "contribución indirecta" como un impuesto que se aplica a los bienes y 
servicios. Sin embargo, la manera de entender estas categorías podía variar durante la primera mitad del siglo XIX, aunque a menudo se entendía que la contribución directa contemplaba alguna especie de proporcionalidad (Serrano Ortega). En los casos aquí referidos, la contribución directa se refiere a impuestos pagados sobre los ingresos individuales o bien sobre el tipo de ocupación del individuo (almacenista, hacendado, jornalero, boticario, etc.). La "capitación" refiere a un cobro aplicado universalmente a todos o a una porción de los contribuyentes/ tributarios de manera que cada individuo paga la misma cantidad.

Archivo Histórico Diocesano de San Cristóbal (AHDSC) Carpeta 5206 Expediente 3, Manifiesto de la Junta Suprema Provisional de Chiapa referente a la necesidad del establecimiento de una contribución directa en los pueblos de la provincia, Ciudad Real, 1 de marzo de 1824. En este momento, las federaciones centroamericana y mexicana cobraban contribuciones directas, aunque con poco impacto (Sarazúa Pérez, 2013; Hernández Jaimes, 2013).

AHDSC Carpeta 5206 Expediente 3, Manifiesto de la Junta Suprema Provisional de Chiapa referente a la necesidad del establecimiento de una contribución directa en los pueblos de la provincia, Ciudad Real, 1 de marzo de 1824. En las Memorias de los gobernadores de 1826, 1827, 28 y 29, se hace referencia a cantidades debidas por la capitación personal desde 1825 sin mencionar al año de 1824, pero hay dos cartas fechadas en 1824 y 1825 que hacen pensar que se empezó a cobrar inmediatamente después de su proclama, además de otro oficio de 1827 que lo refiere de manera contundente ("Memoria", 1827; "Memoria", 1828; "Memoria" 1829; "Memoria", 1830; AHDSC Carpeta 4512 Expediente 2, Carta de Cristoval Rojas a Julián Rojas, Ciudad Real, 27 de marzo de 1824; AHDSC, Carpeta 3781, Exp. 67, Carta de José Mariano Troncoso al señor Robles en la que le comunica que los señores diputados del Congreso Constituyente y demás funcionarios del estado están desempeñando sus cargos sin ningún sueldo. El remitente sugiere a los miembros del ayuntamiento que cobren pronto a los pueblos la contribución, porque de lo contrario el estado está expuesto a sufrir males incalculables. Ciudad Real, 9 de junio de 1825; Centro Universitario de Información y Documentación -Universidad de Ciencias y Artes de Chiapas (CUID), Carpeta 020, Decretos del estado. Año 1827, Circular del ayuntamiento de Tuxtla dirigido a los demás ayuntamientos de los pueblos de partido de Tuxtla, Tuxtla, 17 de mayo de 1827, f. 3). Chiapas a la Secretaría del gobierno del mismo estado, Capital de Chiapas, 3 de mayo de 1827 f. 2 v.

CUID, Carpeta 020, Decretos del estado. Año 1827, ff. 2-3v; Archivo Municipal de La Trinitaria (AMLT), Caja 28-A, Paquete 2, Legajo 11, Expediente 1, Índice general en que se manifiestan por menor inventariados todos los papeles pertenecientes al Archivo de este Pueblo de Zapaluta desde el año de 1825 hasta el presente de 1833. Zapaluta, 31 de diciembre de 1831.

CUID, Carpeta 020, Decretos del gobierno del estado. Año 1827, Oficio del Tesorero general del estado de Chiapas a la Secretaría del gobierno del mismo estado, Capital de Chiapas, 3 de mayo de 1827 , f. 2. 

Presidente de los Estados Unidos Mexicanos, 19 de abril de 1831 f. 52.

"México 28 de abril de 1829", reproducido de Correo, núm. 330, Para-Rayo. de la Capital de Chiapas, núm. 87, 21 de mayo de 1829, ff. 251-252. Es de suponerse que se trata del Correo de la Federación, en el que el entonces ministro de Hacienda tuvo un papel importante.

“Noticias nacionales. Megico 2 de mayo de 1829", Para-Rayo, núm. 89, 4 de junio de 1829, ff. 258-259; "Morelia y mayo 14 de 1829" y "Morelia y mayo 21 de 1829", Para-Rayo, núm. 91, 18 de junio de 1829, ff. 267-269; "Morelia y mayo de 1829", Para-Rayo, núm. 93, 2 de julio de 1829, ff. 274-276; "Secretaría de hacienda", Para-Rayo, núm. 108, 15 de octubre de 1829, f. 332; "Continua la ley sobre contribuciones", núm. 109, 22 de octubre de 1829, ff. 336-337; "Finalisa la ley sobre contribuciones", Para-Rayo, núm.110, 29 de octubre de 1829, ff. 339-340; “Representación. Que la H. legislatura del Estado de Michoacán dirigió en 26 de setiembre de 1829 al Ecsmo. sr. presidente de la república, manifestándole los graves inconvenientes que trahe consigo la observancia del decreto de 15 del mismo mes sobre contribucion directa", núm. 111, 5 de noviembre de 1829, ff. 344-345.

“Finalisa la ley sobre contribuciones", Para-Rayo, número 110, 29 de octubre de 1829, f. 340.

Véase Vázquez sobre esta cuestión en particular y más ampliamente sobre las actitudes reformadoras de José Ignacio Gutiérrez durante su periodo de gobierno.

AHC, imágenes 1189-1199. Reglamento decretado por el Supremo Gobierno del Estado de Chiapas para la formación del Censo general, llenando los objetos del artículo 31 y Ley de 20 de Julio de 1831, 17 de agosto de 1833, f. 1 . El documento es interesante por varias razones, entre otras por incluir una columna de "mujeres contribuyentes" y por solicitar que se calculara el número de personas en cada familia en cada pueblo, especialmente en los pueblos de indígenas. Trens indica que nunca se pudo implementar (Trens 319).

Archivo General de la Nación (AGN), Contribuciones Directas, Caja 193, Exp. 967.38, 1836 Chiapas. [Nota: Al interior de este expediente existen varios documentos. La referencia es el documento núm. 7,] Oficio del Tesorero de Chiapas al Administrador General de Contribuciones Directas, San Cristóbal, 20 de diciembre de 1836, f. 7v.

AGN, Contribuciones Directas, Caja 193, Exp. 967.38, 1836 Chiapas. [Documento 10], Oficio del Administrador Principal de las Rentas Nacionales de San Cristóbal al Administrador General de Contribuciones Directas, San Cristóbal Capital de Chiapa, 11 de noviembre de 1837.

AGN, Contribuciones Directas, Caja 193, exp. 967.38, 1836 Chiapas. [Documento 3], Oficio del Tesorero de Chiapas al Administrador general de las contribuciones directas. San Cristóbal Capital de Chiapa, 4 de octubre de 1836.

AGN, Contribuciones Directas, Caja 193, exp. 967.38, 1836 Chiapas. [Documento 12] Oficio del Administrador general de contribuciones directas, San Cristóbal, 19 de julio de 1838.

AGN, Contribuciones Directas, Caja 195, exp. 969.14, 1842 Personal Chiapas, Oficio del gobernador de Chiapas al Director general de rentas, San Cristóbal, 29 de marzo de 1842.

CUID, Carpeta 85, Decretos del Supremo Gobierno del Estado y Comunicaciones diversas de la prefectura del Oeste de esta misma entidad Año 1846, Decreto del 7 de abril de 1842. 
AGN Contribuciones Directas, Caja 195, exp. 969.14. Oficio del gobernador de Chiapas al Director de Rentas Generales, San Cristóbal, mayo 1842.

AGN Contribuciones Directas, Caja 188, exp. 962.43, 1843 Chiapas Contribuciones de 841 y 842.

AGN Contribuciones Directas, Caja 188, exp. 962.43, 1843 Chiapas Contribuciones de 841 y 842. La información presentada por Jorge Serrano sobre los ingresos departamentales de las contribuciones directas para 1843 resulta en contradicción con estos datos. Es posible que la información en el cuadro citado refiere a lo recaudado, pero no a lo entregado a la Hacienda nacional (Serrano Ortega 153).

AGN Contribuciones Directas, Caja 188, exp. 962.43, 1843 Chiapas Contribuciones de 841 y 842.

Torres Freyermuth menciona la movilización de tropas Chiapalibres en Comitán en 1824, cuya actividad se describió por dos bandas opuestas, de maneras diferentes: o con la intención de cobrar un "empréstito forzoso" o acciones para "sacar dinero con las armas para sostener unas tropas" (78). Así mismo, la misma autora refiere al saqueo de casas por el grupo militar que apoyaba a Joaquín Miguel Gutiérrez en Tuxtla a principios de julio de 1835.

"Partes Oficiales" (es un parte oficial de Pedro Ayerdi, nombrado Jefe Departamental por aclamación popular, enviado el Ministro de Guerra de la Federación Centroamericana del 13 de octubre de 1826), El Indicador, núm. 103, pp. 413-414, 23 de octubre de 1826.

"Partes Oficiales", El Indicador, núm. 103, p. 414, 23 de octubre de 1826. El parte refiere a la muerte de Cirilo Flores y menciona en su descripción de los ánimos de la gente: “Indispuesto el vecindario contra las autoridades del Estado por creer atacaban nuestra Sta. Religión: por los empréstitos forzosos que se estaban exigiendo, y por otras muchas ocurrencias" Sobre las tierras, véase Pollack (2008).

La continuidad se expresa de manera transparente al ver los recibos por las aportaciones de Antonio García Redondo, deán de la iglesia catedral, que acompañan al aviso de un préstamo forzoso de enero de 1828. Estos recibos refieren a contribuciones de 500 pesos ofrecidas el 31 de agosto de 1808, 21 de junio de 1809, 6 de mayo de 1811 y 21 de julio de 1811. AGCA L 2360, E 47911. Aviso de préstamo forzoso a Dr. Antonio García Redondo, 16 de enero de 1828.

Referente a 1828, véase Archivo Histórico de Chiapas (AHC), T III, doc. 42, p. 803 Decreto del gobernador de Chiapas, para colectar de diversos ramos de impuesto, descuentos a sueldos de empleados, etc. la cantidad de \$30,000.00 destinada a auxiliar a la federación de las críticas circunstancias en que se encuentra, manifestando que si no se reúne oportunamente dicha suma, se harán prestamos forzosos, 29 de mayo de 1828.

Sobre 1832, véase AHC, T IV, doc. 63, Decreto autorizando al gobierno a dictar las medidas que juzgue convenientes para reunir caudales "ya sean de distribución directa o de las indirectas", San Cristóbal, 20 de noviembre de 1830. Nótese que el decreto es del 20 de septiembre de 1832 y no del 20 de noviembre de 1830 como se indica en el catálogo del AHC. Una parte oficial, referente a ingresos y egresos de 1832, indica que "no se incluyen lo que se exigió en septiembre y octubre al vecindario por la comandancia militar", "Parte oficial", El Iris de Chiapas, t. 1, núm. 27, p. 107, 18 de marzo de 1833. Es también posible que se aplicara un préstamo asignado a algunos vecinos en noviembre de 1832, como se refiere en El Iris de Chiapas, en un artículo dedicado a criticar al excomandante Gregorio Ortega. “Continúa el comunicado comenzado en el número 37”, El Iris 
de Chiapas, t, 1, núm. 38, pp. 157-158, 3 de junio de 1833 y “Continúa y concluye el comunicado de los números anteriores, El Iris de Chiapas, t. 1, núm. 39, p. 161, 17 de junio de 1833.

En 1835, en medio de un conflicto armado al interior del estado entre los seguidores del Plan de Cuernavaca y los de Joaquín Miguel Gutiérrez, la legislatura decretó un préstamo y los dos bandos intentaron cobrarlo (Torres Freyermuth 178-189). Trens indica que la resistencia al cobro provocó que posteriormente se convirtió en forzoso el préstamo. El gobierno centralista mexicano declaró un préstamo forzoso en octubre de 1836, pero dos meses después, como acto de resistencia, el gobernador del estado de Chiapas, lo rechazó (Ruiz). Sobre 1850, véase CUID, Expediente 112, Decretos del gobierno del estado y otros documentos relativos a la villa de Ocosingo..., Decreto del Congreso de Chiapas, San Cristóbal de las Casas, 11 de julio de 1850.

AGCA Sig. B L 2502 sin número de expediente. Lista de los Ciudadanos de este Pueblo de Santiago Patzicia que han contribuido voluntariam.te la subscripcion patriotica en virtud del decreto que trata de la materia, Patzicía, 18 de febrero de 1824. Taracena Arriola menciona préstamos en 1824 y 1825.

El decreto de 1825 había establecido una tasa progresiva, de medio por ciento sobre "sueldo, renta o beneficio" desde 150 a 700 pesos, $1 \%$ desde 800 a 1,500 pesos y $1.5 \%$ mayor de 1,600 pesos para arriba (Pollack, 2018). Sig. B, L 4125, E 92803, Ordenanza para la recaudación, administración y reparación de agravios del impuesto general, decretado en primero de diciembre de 1823, Guatemala, 22 de enero; AGCA Sig. B L 192, E 4153, Decreto N.o 68 __de 10 de Nov.e de 1825. Establece una contribución directa entre todos lo (sic) CC del Estado, pars al año procimo de 1825 (sic), Tarifa de la cuota que sobre las rentas i utilidades de los Ciudadanos ha impuesto la Asamblea constituyente de Guatemala para cubrir los gastos de la administración en el año de 826 por no alcanzar para ellos las rentas indirectas, f. 14.

La comisión de la Asamblea Legislativa del estado de Guatemala propuso manifestar al congreso centroamericano la importancia de una reforma constitucional que limitaría el voto a las personas con capacidad de pagar la contribución (Sarazúa Pérez, 2012).

Woodward (491 n. 32) cita las Memorias del General Carrera.

Las Memorias (24 y 25-26, n. 1) refiere a una fecha de finales de junio de 1837, pero por las otras fechas mencionadas y aclaraciones del editor, probablemente se refiere a finales de mayo del mismo año. Woodward (491, n. ${ }^{\circ}$ 32) indica que el texto se elaboró en 1863.

“La Asamblea Lejislativa del Estado cerró sus sesiones ordinarias el 31 de Agosto último; y en este acto dijo su Presidente los que sigue:" Semanario de Guatemala, 13 de septiembre de 1836, núms. 19 y 20, p. 79; "La Asamblea Lejislativa de 37: al Mensaje del Gefe del Estado: Leida en el salon del Gobierno el 20 de Febrero, por una comisión de aquel alto cuerpo", El Editor. Periodico de los tribunales, núm. 2, 24 de febrero de 1837, p. 6.

AGCA Sig. B L 2503 E 55632, Algunos individuos y demás del calpul del Pueblo de Chimaltenango solicitan que no sufran de abusos por el cobro de los 12 reales, finales de enero, 1831.

41 AGCA Sig. B L 2503 E 55648, Los miembros de la municipalidad del año previo de Patzicía solicita ser excusados del cobro de la contribución directa, Patzicía, 8 de marzo de 1835. Departamental de Sacatepéquez sobre los esfuerzos de la corporación municipal en el cobro de 
la contribución, 17 de marzo de 1835. Es de notarse que la corporación municipal aquí referida no es la que elaboró el documento anteriormente citado.

AGCA Sig. B L 2503 E 55613. Solicitud del cuerpo municipal que se le permita más tiempo para la entrega de la contribución directa, Patzún, 9 de agosto de 1830.

Las cursivas son del autor. "Parte oficial", Semanario de Guatemala, Alcance al núm. 33, 20 de diciembre de 1836.

AGCA Sig B L 2503 E 55690, Sobre manifestar al Correg.r de Chimaltenango, que varios indígenas del pueblo de Acatenango se han quejado al Gobno. de que los justicias de dicho pueblo tienen ya recaudada la contribucion y la conservan guardada, y ahora la estan volviendo à cobrar, sobre lo cual debe hacer las averiguaciones del caso, 30 de octubre de 1839.

Las cursivas son del autor. “La Asamblea Lejislativa del Estado cerró sus sesiones ordinarias el 31 de Agosto último; y en este acto dijo su Presidente los que sigue:", Semanario de Guatemala, n. ${ }^{\circ} 19$ y 20,13 de septiembre de 1836, p. 83.

"Suplica", El Ciudadano, 2 de abril de 1836, p. 19.

“Del Majistrado Ejecutor del distrito de Sololá", Informe del 7 de julio de 1837, El Editor. Periódico de los tribunales, núm. 17, 3 de agosto de 1837, p. 69; "Comandancia militar de Güegüetenango y Jacaltenango", Informe del 11 de julio de 1837, El Editor. Periódico de los tribunales, núm. 19, 31 de agosto de 1837, pp. 77-78. Creo conveniente notar que por lo menos una de las apreciaciones de Hazel Ingersoll (56-57), publicadas en su tesis de doctorado hace más de cuarenta años sobre esta cuestión puede ser desviante. La referencia que Ingersoll hace a "widespread rioting" en Verapaz, no resulta ser verídica, más allá de una suposición del Magistrado Ejecutor de Verapaz de que los demás pueblos estuvieron de acuerdo con el de Lanquín, que efectivamente corrió violentamente al juez de circuito de Cahabón. "Al Ciudadano Secretario general del Gobierno Supremo del Estado", Informe del juez de circuito de Cahabón y respuesta del Magistrado Ejecutor de Verapaz, El Editor. Periódico de los tribunales, núm. 16, julio 23 de 1837, p. 64. Por otra parte, en el caso huehueteco, no hubo encarcelados, como indica la autora. "Comandancia militar de Güegüetenango y Jacaltenango", Informe del 11 de julio de 1837, El Editor. Periódico de los tribunales, núm. 19, 31 de agosto de 1837, pp. 77-78. No cuestiono la general inquietud en las zonas rurales de Guatemala, pero quiero subrayar que esta probablemente no provenía principalmente de la ley de Hacienda.

El levantamiento se relacionaba con la expropiación de un terreno, de por sí en contención, que se pretendía usar para la construcción de un juzgado, como preveía el código Livingston (Reeves).

50 Sobre la rebelión de Carrera, puede verse Ingersoll; Miceli; Solórzano Fonseca; Woodward; Jefferson, 2000; Jefferson, 2015 y Sarazúa Pérez, 2007.

“Más directamente responsable de la reacción popular fue el establecimiento de un impuesto directo de capitación, reminiscencia del tributo cobrado por los españoles" (Woodward 49).

“Hacienda pública”, Noticioso Guatemalteco, núm. 7, 17 de marzo de 1838, p. 41. 

incluyen lo presentado en este artículo.

AGCA Sig B L 2503 E 55690, Sobre manifestar al Correg.r de Chimaltenango, que varios indígenas del pueblo de Acatenango se han quejado al Gobno. de que los justicias de dicho pueblo tienen ya recaudada la contribucion y la conservan guardada, y ahora la estan volviendo à cobrar, sobre lo cual debe hacer las averiguaciones del caso, 30 de octubre de 1839.

\section{Bibliografía}

\section{Archivos consultados}

Archivo General de Centroamérica (AGCA), Ciudad de Guatemala.

Archivo Histórico de Chiapas (AHC), Biblioteca Manuel Orozco y Berra, Dirección de Estudios Históricos, Instituto Nacional de Antropología e Historia (INAH), Ciudad de México.

Archivo Histórico Diocesano de San Cristóbal, San Cristóbal de las Casas (AHDSC), Chiapas, México.

Archivo Municipal de La Trinitaria (AMLT), La Trinitaria, Chiapas, México.

Centro Universitario de Información y Documentación (CUID) -Universidad de Ciencias y Artes de Chiapas, Tuxtla Gutiérrez, Chiapas, México.

\section{Obras citadas}

Andriveau-Goujon. E. Atlas de Choix, ou Recueil des Meilleures Cartes de Géographie Ancienne et Moderne Dressées par Divers Auteurs. París, Chez J. Andriveau, 1854.

Berghaus, Heinrich. Dr. Heinrich Berghaus' Physikalischer Atlas oder Sammlung von Karten. Gotha, J. Perthes, 1845-1848.

Colton, G. W. y Swainson, R. Colton's general atlas: containing one hundred and eighty steel plate maps and plans, on one hundred and nineteen imperial folio sheets. Nueva York, G. W. \& C. B. Colton, 1869.

Fernández Molina, Manuel. Los tributos en el Reino de Guatemala: 1786-1821. Guatemala, Instituto de Investigaciones Económicas y Sociales, Universidad de San Carlos. 2000.

Fry, Michael. Agrarian Society in the Guatemalan Montaña, 1700-1840 (tesis doctoral). Tulane University, 1988.

García Cubas, Antonio. Atlas geográfico, estadístico e histórico de la República Mexicana, formado por Antonio García Cubas. México, Imprenta de José Mariano Fernández de Lara, 1858

González Alzate, Jorge. A History of Los Altos, Guatemala: A Study of Regional Conflict and National Integration (tesis doctoral). Tulane University, 1994.

Guardino, Peter. Peasants, Politics, and the Formation of Mexico's National State: Guerrero, 18001857. Stanford, Stanford University Press, 1996.

Hall, Carolyn y Héctor Pérez Brignoli. Historial Atlas of Central America. Norman, University of Oklahoma Press, 2003.

Hernández Jaimes, Jesús. Actores indios y Estado nacional: Las rebeliones en el sur de México, 1842-1846. Estudios de Historia Moderna y Contemporánea de México, 26 (2003): 5-44.

Hernández Jaimes, Jesús. La formación de la Hacienda pública mexicana y las tensiones centroperiferia, 1821-1835. México, El Colegio de México/Instituto Mora/UNAM, 2013. 
Ingersoll, Hazel B. The War of the Mountain: A Study of Reactionary Peasant Insurgency in Guatemala, 1837-1873 (Tesis doctoral). George Washington University, 1972.

Jefferson, Ann F. The Rebellion of Mita. Eastern Guatemala in 1837 (Tesis doctoral). University of Massachusetts, 2000.

Jefferson, Ann F. Nuestra América: la visión de la gente parda del Distrito de Mita, 1837. Repensando Guatemala en la Época de Rafael Carrera. El país, el hombre y las coordenadas de su tiempo, editado por Brian Connaughton, México, UAM-Iztapalapa/Editorial Gedisa, 2015, pp. 113-149.

Lauria Santiago, Aldo. Una república agraria. Los campesinos en la economía y la política de El Salvador en el siglo xix, trad. del inglés de Márgara Zablah de Sumán. San Salvador, Consejo Nacional para la Cultura y el Arte, 2003.

Mackenzie, C. James. Resumen de la Historia de San Andrés Xecul. Desde tiempos prehispánicos hasta los finales del siglo 19 (sin publicar), 2002.

Marure, Alejandro. Catálogo de las leyes promulgadas en el estado de Guatemala, desde su erección en 15 de Setiembre de 1824 hasta el 5 de Octubre de 1841. Guatemala, Imprenta de La Paz, 1841.

"Memoria del estado actual en que se hallan los ramos de la administracion publica de las Chiapas" (1827), Capital de Chiapas, Imprenta de la Sociedad, 6 de febrero de 1828 en Julius Fenner, Memorias e Informes de los Gobernadores de Chiapas, 1826-1900 [cd-rom], Tuxtla Gutiérrez, UNICACH/Archivo Histórico de Chiapas/UNAM/IA/ PROIMMSE, 2010.

"Memoria del estado en que se hallan los ramos de la administracion pública del estado de Las Chiapas" (1828), Capital de Chiapas, Imprenta de la Sociedad, 1829, en Julius Fenner, Memorias e Informes de los Gobernadores de Chiapas, 1826-1900 [cd-rom], Tuxtla Gutiérrez, UNICACH/Archivo Histórico de Chiapas/UNAM/IA/PROIMMSE, 2010.

"Memoria del estado en que se hallan los ramos de la administracion publica de las Chiapas" (1829), San Cristoval, Imprenta de la Sociedad, 20 de febrero de 1830, en Julius Fenner, Memorias e Informes de los Gobernadores de Chiapas, 1826-1900 [cd-rom], Tuxtla Gutiérrez, UNICACH/Archivo Histórico de Chiapas/UNAM/IA/PROIMMSE, 2010.

"Memoria del estado en que se hallan los ramos de la administracion publica de las Chiapas", (1830), San Cristoval, Imprenta de la Sociedad, 10 de febrero de 1831, en Julius Fenner, Memorias e Informes de los Gobernadores de Chiapas, 1826-1900 [cd-rom], Tuxtla Gutiérrez, UNICACH/Archivo Histórico de Chiapas/ UNAM/IA/PROIMMSE, 2010.

Memorias del General Carrera 1837 a 1840, editado por Ignacio Solis, Guatemala, Tipografía Sánchez \& De Guise, 1906.

Miceli, Keith L. Rafael Carrera: Defender and Promoter of Peasant Interests in Guatemala, 1837-1848. The Americas, 31, 1(1974): 72-95. Recuperado de https://www.jstor.org/ stable/980382?seq=1\#metadata_info_tab_contents

Piquero, Ygnacio. Breve instrucción sobre las contribuciones directas establecidas en la nación desde el año de 1836. México, Imprenta de Vicente G. Torres, 1845.

Pollack, Aaron. De la contribución directa proporcional a la capitación en la Hispanoamérica republicana: Los límites impuestos por la constitución fiscal. Araucaria. Revista Iberoamericana de Filosofía, Política y Humanidades, 18, 36(2016): 59-86. Recuperado de https://dialnet.unirioja.es/servlet/articulo?codigo $=5781907$ 
Pollack, Aaron. Levantamiento k'iche' en Totonicapán. Los lugares de las políticas subalternas. Guatemala, Asociación para el Avance de las Ciencias Sociales en Guatemala (AVANCSO), 2008.

Pollack, Aaron. Nuevas fronteras y nuevas políticas fiscales. Las primeras contribuciones directas en Guatemala y Chiapas. Estudios Digital, 6, 16(2018): 1-21. Recuperado de http://iihaa.usac.edu.gt/revistaestudios/index.php/ed/article/view/310

Pollack, Aaron. Totonicapán, 1820: ¿Una de las puntas del iceberg? La época de las independencias en Centroamérica y Chiapas: procesos políticos y sociales, coordinado por Aaron Pollack, México, Instituto Mora/ Universidad Autónoma Metropolitana, México, DF., 2013, pp. 189-223.

Reeves, René. Ladinos with Ladinos, Indians with Indians: Land, Labor, and Regional Ethnic Conflict in the Making of Guatemala. Stanford, Stanford University Press, 2006.

Rodríguez, Mario. The Livingston Codes in the Guatemala Crisis of 1837-1838. Nueva Orleans, Tulane University, 1955.

Ruiz Abreu, Carlos E. (Coord.). Historia del H. Congreso del Estado de Chiapas, Tuxtla Gutiérrez, Congreso del Estado de Chiapas, 1994.

Sánchez Rafael, Miguel Ángel. Formación de la Hacienda pública en Chiapas, 1826-1833. Coloquio El siglo XIX en Guatemala y Chiapas. Acercamientos históricos e historiográficos. San Cristóbal de Las Casas, Chiapas, México, 28 y 29 de septiembre de 2017.

Sánchez Rodríguez, Martín. Política fiscal y organización de la Hacienda pública durante la república centralista en México, 1836-1844. De colonia a nación. Impuestos y política en México, 1750-1860, compilado por Carlos Marichal y Daniela Marino, México, El Colegio de México, 2001, 189-214.

Sarazúa Pérez, Juan Carlos. Territorialidad, comercio y conflicto al Este de Guatemala: Santa Rosa, 1750-1851 (tesis de licenciatura). Escuela de Historia-Universidad de San Carlos de Guatemala, 2007.

Sarazúa Pérez, Juan Carlos. Finanzas estatales en Guatemala, 1823-1850. Independencias, Estados y Política(s) en la Centroamérica del Siglo xix. Las Huellas Históricas del Bicentenario, editado por David Díaz Arias y Ronny Viales Hurtado, San José, Universidad de Costa Rica, 2012, pp. 65-87.

Sarazúa Pérez, Juan Carlos. Recolectar, administrar y defender: la construcción del Estado y las resistencias regionales en Guatemala, 1800-1871 (tesis doctoral). Universitat Pompeu Fabra, 2013.

Sarazúa Pérez, Juan Carlos. Tributación, ciudadanía y servicio militar en Guatemala, 18211863. Pueblos indígenas en Latinoamérica. Incorporación, conflicto, ciudadanía y representación. Siglo XIX, coordinado por Leticia Reina, México, INAH, 2015, 117-157.

Serrano Ortega, José Antonio. Igualdad, uniformidad, proporcionalidad. Contribuciones directas y reformas fiscales en México, 1810-1846. México: El Colegio de Michoacán/Instituto Mora, 2007.

Solórzano Fonseca, Juan Carlos. Rafael Carrera, ¿Reacción conservadora o revolución campesina? Anuario de Estudios Centroamericanos, 12(1987): 5-35. Recuperado de https:// revistas.ucr.ac.cr/index.php/anuario/article/view/2853

Taracena Arriola, Arturo. Invención criolla, sueño ladino, pesadilla indígena. Los Altos de Guatemala: de región a Estado, 1740-1850. San José, Editorial Porvenir/Centro de Investigaciones Regionales de Mesoamérica, 2003. 
Taracena Arriola, Arturo, Pira, Juan Pablo y Marcos, Celia. Los departamentos y la construcción del territorio nacional en Guatemala, 1825-2002. Guatemala, Asociación de Investigación y Estudios Sociales (ASIES), 2003.

Taracena Arriola, Luis Pedro. ¿Guerra estatal o guerra de ciudades? Movilización militar, recaudación y discurso político, 1826-1829. La primera guerra federal centroamericana, 1826-1829. Naciones y estados, republicanismo y violencia, editado por Arturo Taracena Arriola, Guatemala, Universidad Rafael Landívar/Universidad Autónoma Metropolitana/CEPHCIS-UNAM, 2015, pp. 1-53.

Torres Freyermuth, Amanda Úrsula. Los hombres de bien. Un estudio de la élite política en Chiapas (1824-1835). San Cristóbal de las Casas, Chiapas, Centro de Investigaciones Multidisciplinarias sobre Chiapas y la Frontera Sur (CIMSUR)-UNAM, 2017.

Torres Medina, Javier. Centralismo y reorganización. La hacienda pública y la administración durante la primera república central de México, 1835-1842. México, Instituto Mora, 2013.

Trens, Manuel B. Historia de Chiapas. Desde los tiempos más remotos hasta la caída del Segundo Imperio (i...1867?). Tuxtla Gutiérrez, Consejo Estatal para la Cultura y las Artes de Chiapas, 1999.

Vázquez Olivera, Mario Rafael. Chiapas mexicana. La gestión de la frontera entre México y Guatemala durante la primera mitad del siglo XIX, Centro de Investigación sobre América Latina y el Caribe (CIALC)-UNAM/Centro de Investigaciones Multidisciplinarias sobre Chiapas y la Frontera Sur (CIMSUR)-UNAM, 2018.

Vandermaelen, Philippe, S. G. H Hassel y Henri Ode. Atlas universel de géographie physique, politique, statistique et minéralogique, sur l'échelle de 1:1,641,836 ou d'une ligne par 1900 toises. 6. Partie. Bruselas: P. M. G Vandermaelen Editeur, 1827.

Woodward, Ralph Lee Jr. Rafael Carrera and the Emergence of the Republic of Guatemala, 1821-1871. Athens, University of Georgia Press, 2008.

Aaron Pollack. Estadounidense. Doctor en Geografía por la Universidad Clark, Massachusetts, Estados Unidos. Actualmente se desempeña como profesor e investigador del Centro de Investigaciones y Educación Superior en Antropología Superior (CIESAS), México.

Contacto: aapollack@gmail.com

ORCID: 0000-0002-0456-8598 
